\title{
Perinatal and maternal outcomes by planned place of birth for healthy women with low risk pregnancies: the Birthplace in England national prospective cohort study
} (c) (1) \& 8 OPEN ACCESS

\author{
Birthplace in England Collaborative Group
}

\begin{abstract}
Objective To compare perinatal outcomes, maternal outcomes, and interventions in labour by planned place of birth at the start of care in labour for women with low risk pregnancies.

Design Prospective cohort study.

Setting England: all NHS trusts providing intrapartum care at home, all freestanding midwifery units, all alongside midwifery units (midwife led units on a hospital site with an obstetric unit), and a stratified random sample of obstetric units.

Participants 64538 eligible women with a singleton, term ( $\geq 37$ weeks gestation), and "booked" pregnancy who gave birth between April 2008 and April 2010. Planned caesarean sections and caesarean sections before the onset of labour and unplanned home births were excluded.

Main outcome measure A composite primary outcome of perinatal mortality and intrapartum related neonatal morbidities (stillbirth after start of care in labour, early neonatal death, neonatal encephalopathy, meconium aspiration syndrome, brachial plexus injury, fractured humerus, or fractured clavicle) was used to compare outcomes by planned place of birth at the start of care in labour (at home, freestanding midwifery units, alongside midwifery units, and obstetric units).
\end{abstract}

Results There were 250 primary outcome events and an overall weighted incidence of 4.3 per 1000 births $(95 \% \mathrm{Cl} 3.3$ to 5.5). Overall, there were no significant differences in the adjusted odds of the primary outcome for any of the non-obstetric unit settings compared with obstetric units. For nulliparous women, the odds of the primary outcome were higher for planned home births (adjusted odds ratio $1.75,95 \% \mathrm{Cl} 1.07$ to 2.86 ) but not for either midwifery unit setting. For multiparous women, there were no significant differences in the incidence of the primary outcome by planned place of birth. Interventions during labour were substantially lower in all non-obstetric unit settings. Transfers from non-obstetric unit settings were more frequent for nulliparous women (36\% to $45 \%$ ) than for multiparous women ( $9 \%$ to $13 \%$ ).

Conclusions The results support a policy of offering healthy women with low risk pregnancies a choice of birth setting. Women planning birth in a midwifery unit and multiparous women planning birth at home experience fewer interventions than those planning birth in an obstetric unit with no impact on perinatal outcomes. For nulliparous women, planned home births also have fewer interventions but have poorer perinatal outcomes.

\section{Introduction}

The relative benefits and risks of birth in different settings have been widely debated in recent years. ${ }^{1-7}$ A problem when trying to evaluate the effect of birth setting on perinatal outcomes has been the use of actual place of birth rather than planned place of birth to define comparison groups. Available evidence summarised in the National Institute for Health and Clinical Excellence (NICE) guideline on intrapartum care indicates that, although there is a higher likelihood of a vaginal birth with less intervention for healthy women who plan to give birth at home or in a midwifery unit compared with an obstetric unit, there is a lack of good quality evidence comparing the risk of rare but serious adverse outcomes by birth setting. ${ }^{8-10}$

The primary objective of this study was to compare intrapartum and early neonatal mortality and specific neonatal morbidities for births planned at home, in freestanding midwifery units, and in "alongside midwifery units" (midwife led units on a hospital site with an obstetric unit) with births planned in obstetric units, for babies of women judged to be at low risk of complications before the onset of labour.

In England almost all maternity care is provided by the National Health Service (NHS) and is free at the point of care. Births outside an obstetric unit are relatively uncommon. Of women giving birth in 2007, around $8 \%$ gave birth outside an obstetric unit $-2.8 \%$ at home, around $3 \%$ in alongside midwifery units, and just under $2 \%$ in freestanding midwifery units. ${ }^{11}$ 


\section{Methods}

The study was a prospective cohort study with planned place of birth at the start of care in labour as the exposure (home, freestanding midwifery unit, alongside midwifery unit, or obstetric unit). ${ }^{12}$ Women were included in the group in which they planned to give birth at the start of care in labour regardless of whether they were transferred during labour or immediately after birth. We compared each of the non-obstetric unit groups (home, freestanding midwifery unit, alongside midwifery unit) with the obstetric unit group in order to establish whether outcomes differed from the obstetric unit group in each of these settings.

The primary outcome was a composite of perinatal mortality and specific neonatal morbidities: stillbirth after the start of care in labour, early neonatal death, neonatal encephalopathy, meconium aspiration syndrome, brachial plexus injury, fractured humerus, and fractured clavicle. ${ }^{13}$ This composite measure was designed to capture outcomes that may be related to the quality of intrapartum care, including morbidities associated with intrapartum asphyxia and birth trauma.

Secondary outcomes included neonatal and maternal morbidities, maternal interventions, and mode of birth (see appendix 1 on bmj.com for a complete list of pre-specified outcomes and appendix 2 for details of the derivation of outcome variables requiring clinical review).

Women were classified as "healthy women with low risk pregnancies" if, before the onset of labour, they were not known to have any of the medical or obstetric risk factors listed in the NICE intrapartum care guideline. These are considered to increase risk for the woman or baby, and care in an obstetric unit would be expected to reduce this risk. ${ }^{8}$

\section{Setting and participants}

All women attended by an NHS midwife during labour in their planned place of birth, for any amount of time, were eligible for inclusion with the exception of women who had an elective caesarean section or caesarean section before the onset of labour, presented in preterm labour (<37 weeks' gestation), had a multiple pregnancy, or who were "unbooked" (that is, received no antenatal care). Stillbirths occurring before the start of care in labour were excluded.

We aimed to collect data in every NHS trust in England providing home birth services, every freestanding midwifery unit, every alongside midwifery unit, and a random sample of obstetric units, stratified by unit size and geographical region.

Participating units or trusts collected data for varying periods within the study period of 1 April 2008 to 30 April 2010. The target sample size was at least 57000 women overall: 17000 planned home births, 5000 planned alongside midwifery unit births, 5000 planned freestanding midwifery unit births, and 30 000 planned obstetric unit births (of which we estimated 20000 would be low risk). Sample size calculations are provided in the study protocol (appendix 1 on bmj.com).

Research ethics committee approval was obtained from the Berkshire Research Ethics Committee (MREC ref 07/H0505/151) and did not require consent to be sought from participants.

\section{Data collection}

Each participating unit or trust had a local coordinating midwife. Data collection forms for the study were designed to be started by the midwife providing intrapartum care, to accompany the woman if she was transferred, and to be completed on or after the fifth postnatal day (see appendix 3 on bmj.com).

Additional neonatal and maternal morbidity forms were completed when the initial form indicated that an adverse outcome had occurred or that the baby or mother had been admitted for higher level care. The morbidity forms validated outcome events and captured additional events which were diagnosed after the end of labour care. These forms were completed by midwives using information from the woman's or baby's medical notes or computer records with assistance from neonatal unit staff.

Each unit or trust provided monthly counts of eligible women, which enabled response rates to be calculated. Some forms were completed retrospectively for eligible women who were missed during the period of data collection in some units or trusts.

Detailed data collection and data management procedures are described elsewhere. ${ }^{13}$

\section{Statistical analysis}

The analysis population included all eligible healthy women with low risk pregnancies for whom data were collected. Women were analysed in the group in which they planned to give birth, with the obstetric unit group as the reference.

The stratification used in the random sampling of obstetric units was not taken into account in the analysis because obstetric units were the only unit type sampled. Ignoring the stratified sampling does not affect point estimates and may have resulted in slightly overestimated standard errors. ${ }^{14}$ Robust variance estimation was used to allow for the clustered nature of the data within units and trusts. Probability weights were used to account for differences in the probability of a woman being selected for inclusion in the study arising from differences in each unit or trust's period of participation and the stratum-specific probabilities of selection of obstetric units.

Logistic regression was used to calculate the odds ratios and confidence intervals for each outcome, accounting for the clustering and sample weights. We adjusted for maternal age, ethnic group, understanding of English, marital or partner status, body mass index in pregnancy, index of multiple deprivation score, parity and gestational age at birth (see appendix 4 on bmj.com for categorisation). For each outcome, we report the number of events, the number of births, the weighted incidence, an unadjusted odds ratio restricted to births included in the adjusted analysis, and an adjusted odds ratio controlling for potential confounders.

As specified in the protocol, $95 \%$ confidence intervals are presented for the primary outcome and $99 \%$ confidence intervals are presented for all secondary outcomes.

We conducted a pre-specified subgroup analysis to examine whether the effect of planned place of birth was consistent for nulliparous and multiparous women. We performed an overall test for statistical interaction between planned place of birth and parity using the Wald test and report the $\mathrm{P}$ values for each interaction term (one for each planned place of birth) separately.

Two pre-specified sensitivity analyses were performed to assess the robustness of the results. Firstly, we restricted the analysis to units or trusts that included at least $85 \%$ of eligible women (see appendix 5 on bmj.com). Secondly, we used propensity score methods to explore more fully the effect on the primary outcome of imbalances in the baseline characteristics of women in different birth settings (see appendix 6 on bmj.com). ${ }^{15}$

Stata version 11.1 was used for all analyses. ${ }^{16}$ 


\section{Results}

We collected data on 79774 eligible women, of whom 64538 were low risk, from 142 (97\%) of the 147 trusts providing home birth services, 53/56 (95\%) of freestanding midwifery units, $43 / 51(84 \%)$ of alongside midwifery units, and a sample of 36 obstetric units (figure $\Downarrow$ ). Of the initial sample of 37 obstetric units, five did not agree to participate and were replaced by resampling from within the same stratum, and one failed to establish data collection successfully. Overall $74 \%$ (203/274) of participating units or trusts achieved the target response rate of $85 \%$ or more. More than $96 \%$ of records had complete data relating to the primary outcome and confounder variables (see appendix 7 on bmj.com). Based on data recorded on the initial forms, neonatal morbidity data were requested for $3.5 \%$ of births, and 94\% (2615/2770) of these forms were returned; maternal morbidity data were requested for $1.9 \%$ of births, and 93\% (1388/1490) of these forms were returned.

The characteristics of women and their babies varied by planned place of birth (table $1 \Downarrow$ ). Compared with the obstetric unit group, women planning to give birth at home were more likely to be older, white, have a fluent understanding of English, and live in a more socioeconomically advantaged area. The characteristics of women in the freestanding midwifery unit and alongside midwifery unit groups tended to fall between the obstetric unit and home birth groups, with women in the alongside midwifery unit group generally more similar to the obstetric unit group. The biggest difference between the groups was for parity: $27 \%$ of the planned home birth women were nulliparous compared with $46 \%$ of the freestanding midwifery unit women, $50 \%$ of the alongside midwifery unit women, and $54 \%$ of the obstetric unit women.

There were marked differences between planned places of birth in the proportion of women with complicating conditions identified by the attending midwife at the start of care in labour (table $1 \Downarrow$ ). Almost $20 \%$ of women in the obstetric unit group had at least one complicating condition noted at the start of care in labour, compared with $\leq 7 \%$ in each of the other settings. This finding was unexpected and suggested that the risk profile of the "low risk women" varied between the different groups.

Before the analysis of the outcomes, the co-investigators and independent advisory group agreed to modify the analysis plan to include additional analyses of outcomes restricted to women without complicating conditions at the start of care in labour.

For the three non-obstetric unit settings, transfer rates were much higher for nulliparous women (36\% to $45 \%)$ than for multiparous women (9\% to $13 \%$ ) (table $2 \Downarrow$ ). The timing of transfer, before or after birth, also varied by planned place of birth and parity (table 2).

There were 250 primary outcome events and an overall weighted incidence of 4.3 per 1000 births (95\% confidence interval 3.3 to 5.5$)$ (table $3 \Downarrow$ ). Intrapartum stillbirths and early neonatal deaths accounted for $13 \%$ of events, neonatal encephalopathy for $46 \%$, meconium aspiration syndrome for $30 \%$, brachial plexus injury for $8 \%$, and fractured humerus or clavicle for $4 \%$ (see appendix 8 on bmj.com for distributions by planned place of birth).

Overall, there were no significant differences in the odds of the primary outcome for births planned in any of the non-obstetric unit settings compared with planned births in obstetric units (table $3 \Downarrow$ ). For the restricted sample of women without any complicating conditions at the start of care in labour, the odds of a primary outcome event were higher for births planned at home compared with planned obstetric unit births (adjusted odds ratio $1.59,95 \%$ confidence interval 1.01 to 2.52 ) but there was no evidence of a difference for either freestanding or alongside midwifery units compared with obstetric units.

In the subgroup analysis by parity, the odds of the primary outcome for nulliparous women was higher for planned home births than for planned obstetric unit births (adjusted odds ratio $1.75,1.07$ to 2.86 ; table $3 \Downarrow$ ). The strength of this association was increased when the sample was restricted to women with no complicating conditions at the start of care in labour (adjusted odds ratio $2.80,1.59$ to 4.92 ). There were no significant differences in the odds of the primary outcome for nulliparous women in the freestanding midwifery unit or alongside midwifery unit groups compared with the obstetric unit group. For multiparous women there was no evidence of a difference in the primary outcome by planned place of birth. The overall test for interaction (heterogeneity) was of borderline statistical significance for all women $(\mathrm{P}=0.06)$, and was significant for women with no complicating conditions at the start of care in labour $(\mathrm{P}=0.03)$. The pairwise tests for each non-obstetric unit birth setting versus the obstetric unit group showed that this interaction was only statistically significant for the home birth group (all women $\mathrm{P}=0.01$, no complicating conditions $\mathrm{P}=0.006$ ), indicating that the differences seen are unlikely to be due to chance variation.

Most individual perinatal outcomes were rare, and adjusted odds ratios could not be estimated because of the small numbers of events (see appendix 8 on bmj.com for individual perinatal outcomes). Babies were significantly more likely to be breast fed at least once for planned births at home and at freestanding midwifery units compared with planned obstetric unit births.

The odds of receiving individual interventions (augmentation, epidural or spinal analgesia, general anaesthesia, ventouse or forceps delivery, intrapartum caesarean section, episiotomy, active management of the third stage) were lower in all three non-obstetric unit settings, with the greatest reductions seen for planned home and freestanding midwifery unit births (table $4 \Downarrow$ ). The proportion of women with a "normal birth" (birth without induction of labour, epidural or spinal analgesia, general anaesthesia, forceps or ventouse delivery, caesarean section, or episiotomy ${ }^{9}{ }^{10}$ ) varied from $58 \%$ for planned obstetric unit births to $76 \%$ in alongside midwifery units, $83 \%$ in freestanding midwifery units, and $88 \%$ for planned home births; the adjusted odds of having a "normal birth" were significantly higher in all three non-obstetric unit settings (table $5 \Downarrow$ ). For other maternal outcomes (third or fourth degree perineal trauma, maternal blood transfusion, and maternal admission to higher level care), there was no consistent relation with planned place of birth, although these adverse outcomes were generally lowest for planned births in freestanding midwifery units (table $4 \Downarrow$ and appendix 8 on bmj.com).

\section{Sensitivity analyses}

When the analysis was restricted to units or trusts with a response rate of at least $85 \%$, the higher odds of the primary outcome for nulliparous women in the planned home birth group remained, and the strength of this association increased (appendix 5 on bmj.com). The odds of the primary outcome were also higher for nulliparous women in freestanding midwifery units compared with obstetric units for the subgroup of women without any complicating conditions at the start of care in labour (adjusted odds ratio 2.29, 1.17 to 4.47; test for heterogeneity $\mathrm{P}=0.07$ ).

The propensity score analyses did not affect the interpretation of the results and are described in detail in appendix 6 on bmj.com. 


\section{Discussion \\ Principal findings}

The incidence of adverse perinatal outcomes was low in all settings. There was no difference overall between birth settings in the incidence of the primary outcome (composite of perinatal mortality and intrapartum related neonatal morbidities), but there was a significant excess of the primary outcome in births planned at home compared with those planned in obstetric units in the restricted group of women without complicating conditions at the start of care in labour. In the subgroup analysis stratified by parity, there was an increased incidence of the primary outcome for nulliparous women in the planned home birth group (weighted incidence 9.3 per 1000 births, $95 \%$ confidence interval 6.5 to 13.1) compared with the obstetric unit group (weighted incidence 5.3, 3.9 to 7.3 ). The sensitivity analysis restricted to units or trusts with a high response rate suggested some uncertainty around the risk of the primary outcome for planned births in freestanding midwifery units for nulliparous women, but this may have been a chance finding. For multiparous women, there were no significant differences in the primary outcome between birth settings.

Women with planned births at home or in freestanding or alongside midwifery units were significantly less likely than those with planned births in obstetric units to have an instrumental or operative delivery or to receive medical interventions such as augmentation, epidural or spinal analgesia, general anaesthesia, or episiotomy and significantly more likely to have a "normal birth."

\section{Strengths and limitations of study}

The strengths of the study include the ability to compare outcomes by the woman's planned place of birth at the start of care in labour, the high participation of midwifery units and trusts in England, the large sample size and statistical power to detect clinically important differences in adverse perinatal outcomes, the minimisation of selection bias through achievement of a high response rate and absence of self selection bias due to non-consent, the ability to compare groups that were similar in terms of identified clinical risk (according to current clinical guidelines) and to further increase the comparability of the groups by conducting an additional analysis restricted to women with no complicating conditions identified at the start of care in labour, and the ability to control for several important potential confounders.

The weaknesses of the study include the use of a composite primary outcome measure, because of the low event rates for individual perinatal outcomes. We cannot rule out the possibility that the use of a composite may have concealed important differences in outcomes between planned places of birth, such as less severe outcomes in a particular setting. However, examination of the distribution of outcomes by planned place of birth did not suggest that this was the case. In addition, although many of the outcomes included in the composite are likely to reflect problems which occur during labour and birth, their long term implications for the baby are uncertain. For example, although moderate and severe neonatal encephalopathy are associated with development of cerebral palsy and long term morbidity, mild encephalopathy has not been associated with detectable longer term impacts. ${ }^{18}$

The generalisability of these findings to other settings is uncertain. In England, planned birth outside an obstetric unit remains uncommon, despite this being an available option for a number of years. Care is almost always provided by trained
NHS midwives, although they have varying levels of experience of providing care in these settings. There are clear referral pathways to obstetric units if complications occur, using a comprehensive ambulance network with trained staff. In this regard, birth outside an obstetric unit can be described as an integrated aspect of maternity care, although it is possible that the low levels of provision in some areas may decrease the level of integration in practice. Our findings may not apply to countries where care is provided very differently.

\section{Conclusions and policy implications}

Our results support a policy of offering healthy nulliparous and multiparous women with low risk pregnancies a choice of birth setting. Adverse perinatal outcomes are uncommon in all settings, while interventions during labour and birth are much less common for births planned in non-obstetric unit settings. For nulliparous women, there is some evidence that planning birth at home is associated with a higher risk of an adverse perinatal outcome. A substantial proportion of women having their first baby who plan to give birth in a non-obstetric unit setting are transferred to an obstetric unit.

These results will enable women and their partners to have informed discussions with health professionals in relation to clinical outcomes and planned place of birth. For policy makers, the results are important to inform decisions about service provision and commissioning. The relative cost effectiveness of the different birth settings will also be of interest to policy makers and is being compared in another component of the Birthplace Research Programme. ${ }^{19}$

Further research is needed into the avoidability of adverse perinatal outcomes, the effect of staffing and service configuration on outcomes, and more detailed analyses of transfers from non-obstetric unit settings. It is unfortunate that routine maternity information systems are not currently of a sufficiently high quality to enable the analyses presented here to be repeated without carrying out another large prospective cohort study.

The Birthplace in England Collaborative Group includes co-investigators, researchers, project staff, and coordinating midwives who contributed to the research programme. Members are listed in appendix 9 on bmj.com.

Contributors: Members of the writing committee for this paper were Peter Brocklehurst (professor of perinatal epidemiology, National Perinatal Epidemiology Unit (NPEU), University of Oxford; professor of women's health, Institute for Women's Health, University College London (UCL)); Pollyanna Hardy (senior trials statistician, NPEU); Jennifer Hollowell (epidemiologist, NPEU); Louise Linsell (senior medical statistician, NPEU); Alison Macfarlane (professor of perinatal health, City University London); Christine McCourt (professor of maternal and child health, City University London); Neil Marlow (professor of neonatal medicine, UCL); Alison Miller (programme director and midwifery lead, Confidential Enquiry into Maternal and Child Health (CEMACH)); Mary Newburn (head of research and information, National Childbirth Trust (NCT)); Stavros Petrou (health economist, NPEU; professor of health economics, University of Warwick); David Puddicombe (researcher, NPEU); Maggie Redshaw (senior research fellow, social scientist, NPEU); Rachel Rowe (researcher, NPEU); Jane Sandall (professor of social science and women's health, King's College London); Louise Silverton (deputy general secretary, Royal College of Midwives (RCM)); and Mary Stewart (research midwife, NPEU; senior lecturer, King's College London, Florence Nightingale School of Nursing and Midwifery). $\mathrm{JH}, \mathrm{DP}$, and PB drafted the manuscript. PB, AM, CM, NM, AM, MN, $\mathrm{SP}, \mathrm{MR}, \mathrm{JS}$, and LS were involved in the conception and design of the 


\section{What is already known on this topic}

Healthy women who plan to give birth at home or in a midwifery unit are more likely to have a vaginal birth with less intervention compared with women who plan to give birth in an obstetric unit

There is a lack of good quality evidence comparing the risk of rare but serious adverse perinatal outcomes in these settings

\section{What this study adds}

For healthy women with low risk pregnancies, the incidence of adverse perinatal outcomes is low in all birth settings For healthy multiparous women with a low risk pregnancy, there are no differences in adverse perinatal outcomes between planned births at home or in a midwifery unit compared with planned births in an obstetric unit

For healthy nulliparous women with a low risk pregnancy, the risk of an adverse perinatal outcome seems to be higher for planned births at home, and the intrapartum transfer rate is high in all settings other than an obstetric unit

study. PB, JH, DP, RR, and MS were part of the project management team that coordinated data collection for the study. DP, LL, and JH wrote the statistical analysis plan; DP conducted the main analyses; LL conducted the propensity score analysis and provided statistical advice; and $\mathrm{PH}$ provided statistical advice. All authors had access to all data sources, contributed to the interpretation of results, commented on the report, and approved the final version for publication. PB is the guarantor. Funding: This study combines the Evaluation of Maternity Units in England study, funded by the National Institute for Health Research Service Delivery and Organisation (NIHR SDO) programme, and the Birth at Home in England study funded by the Department of Health Policy Research Programme (DH PRP). The funders had no role in the study design, data collection, data analysis, data interpretation, or writing of the report. The views expressed are not necessarily those of the funders.

Competing interest: All authors have completed the Unified Competing Interest form at http://www.icmje.org/coi_disclosure.pdf (available on request from the corresponding author) and declare: no support from any organisation for the submitted work; no financial relationships with any organisations that might have an interest in the submitted work in the previous three years; no other relationships or activities that could appear to have influenced the submitted work .

Ethical approval: Approval was obtained from the Berkshire Research Ethics Committee (MREC ref 07/H0505/151) and did not require consent to be sought from participants.

Data sharing: No additional data available.

1 De Jonge A, van der Goes BY, Ravelli AC, Amelink-Verburg MP, Mol BW, Nijhuis JG, et al. Perinatal mortality and morbidity in a nationwide cohort of 529,688 low-risk planned home and hospital births. BJOG 2009:116:1177-84

2 Janssen PA, Saxell L, Page LA, Klein MC, Liston RM, Lee SK. Outcomes of planned home birth with registered midwife versus planned hospital birth with midwife or physician. CMAJ 2009;181:377-83

3 Lindgren HE, Radestad IJ, Christensson K, Hildingsson IM. Outcome of planned home births compared to hospital births in Sweden between 1992 and 2004. A population-based register study. Acta Obstet Gynecol Scand 2008:87:751-9.

4 Mori R, Dougherty M, Whittle M. An estimation of intrapartum-related perinatal mortality rates for booked home births in England and Wales between 1994 and 2003. BJOG 2008;115:554-9.
5 Wax JR, Lucas FL, Lamont M, Pinette MG, Cartin A, Blackstone J. Maternal and newborn outcomes in planned home birth vs planned hospital births: a meta-analysis. Am J Obstet Gynecol 2010;203:243.e1-8.

6 Hodnett ED, Downe S, Walsh D, Weston J. Alternative versus conventional institutional settings for birth. Cochrane Database Syst Rev 2010;(9):CD000012.

7 Gyte G, Dodwell M, Newburn M, Sandall J, Macfarlane A, Bewley S. Estimating intrapartum-related perinatal mortality rates for booked home births: when the 'best' available data are not good enough. BJOG 2009;116:933-42.

8 National Institute for Health and Clinical Excellence (NICE). Intrapartum care of healthy women and their babies during childbirth. National Collaborating Centre for Women's and Children's Health. RCOG, 2007. www.nice.org.uk/nicemedia/pdf/IPCNICEguidance.pdf

9 Werkmeister G, Jokinen M, Mahmood T, Newburn M. Making normal labour and birth a reality—developing a multidisciplinary consensus. Midwifery 2008;24:256-9.

10 Maternity Care Working Party. Making normal birth a reality. NCT, RCM, and RCOG, 2007. www.rcog.org.uk/womens-health/clinical-guidance/making-normal-birth-reality

11 Redshaw M, Rowe R, Schroeder L, Puddicombe D, Macfarlane A, Newburn M, et al. Mapping maternity care. The configuration of maternity care in England. Birthplace in England research programme. Final report part 3: NIHR service delivery and organisation programme, 2011. www.sdo.nihr.ac.uk/projdetails.php?ref=08-1604-140

12 National Perinatal Epidemiology Unit (NPEU). The Birthplace in England research programme report of component study 1 : terms and definitions. 2007. www.npeu.ox.ac. uk/birthplace/component-studies/tdc

13 Hollowell J, Puddicombe D, Rowe R, Linsell L, Hardy P, Stewart M, et al. The Birthplace national prospective cohort study: perinatal and maternal outcomes by planned place of birth. Birthplace in England research programme. Final report part 4: NIHR service delivery and organisation programme, 2011. www.sdo.nihr.ac.uk/projdetails.php?ref=08-1604-140 and organisation programme, 2011. www.sdo.nihr.ac.uk/projdetails.php?ref $=08-1604-140$
O'Donnell O, van Doorslaer E, Wagstaff A, Lindelow M. Multivariate analysis of health survey data: analyzing health equity using household survey data. World Bank, 2008.

15 D'Agostino RB Jr. Propensity score methods for bias reduction in the comparison of a treatment to a non-randomized control group. Stat Med 1998;17:2265-81.

16 StataCorp. Stata statistical software: release 11. StataCorp, 2009.

17 Cole TJ, Freeman JV, Preece MA. British 1990 growth reference centiles for weight, height, body mass index and head circumference fitted by maximum penalized likelihood. Stat Med 1998;17:407-29.

18 Robertson CM, Finer NN. Long-term follow-up of term neonates with perinatal asphyxia. Clin Perinatol 1993;20:483-500.

19 Schroeder L, Petrou S, Patel N, Hollowell J, Puddicombe D, Redshaw M, et al. Birthplace cost-effectiveness analysis of planned place of birth: individual level analysis. Birthplace in England research programme. Final report part 5: Service delivery and organisation programme, 2011. www.sdo.nihr.ac.uk/projdetails. php?ref=08-1604-140

Accepted: 11 November 2011

\section{Cite this as: BMJ 2011:343:d7400}

This is an open-access article distributed under the terms of the Creative Commons Attribution Non-commercial License, which permits use, distribution, and reproduction in any medium, provided the original work is properly cited, the use is non commercial and is otherwise in compliance with the license. See: http://creativecommons.org/licenses/bync/2.0/ and http://creativecommons.org/licenses/by-nc/2.0/legalcode. 


\section{Tables}

Table 1/ Characteristics of healthy women with low risk pregnancies by their planned place of birth at start of care in labour. Values are numbers (percentages) of women unless stated otherwise

\begin{tabular}{|c|c|c|c|c|}
\hline & Obstetric unit ( $n=19$ 706) & Home $(n=16840)$ & $\begin{array}{l}\text { Freestanding midwifery unit } \\
\qquad(n=11282)\end{array}$ & $\begin{array}{l}\text { Alongside midwifery unit } \\
\qquad(n=16 \quad 710)\end{array}$ \\
\hline \multicolumn{5}{|l|}{ Maternal age (years): } \\
\hline Mean (SD) & $28.2(6.0)$ & $31.1(5.2)$ & $28.8(5.8)$ & $28.3(5.7)$ \\
\hline$<20$ & $1506(7.7)$ & $218(1.3)$ & $677(6.0)$ & $1069(6.4)$ \\
\hline $20-24$ & $4251(21.6)$ & $1706(10.2)$ & $2132(18.9)$ & 3489 (20.9) \\
\hline $25-29$ & $5701(29.0)$ & $4346(25.9)$ & $3267(29.0)$ & $5001(30.0)$ \\
\hline $30-34$ & $5063(25.7)$ & $5848(34.8)$ & $3248(28.8)$ & $4582(27.5)$ \\
\hline $35-39$ & $2640(13.4)$ & $4017(23.9)$ & $1690(15.0)$ & $2232(13.4)$ \\
\hline$\geq 40$ & $520(2.6)$ & $671(4.0)$ & $254(2.3)$ & $299(1.8)$ \\
\hline Missing & 25 & 34 & 14 & 38 \\
\hline \multicolumn{5}{|l|}{ Ethnic group: } \\
\hline White & $16068(81.7)$ & $15937(94.8)$ & $10329(91.6)$ & $13485(80.9)$ \\
\hline Indian & $477(2.4)$ & $67(0.4)$ & $87(0.8)$ & $509(3.1)$ \\
\hline Pakistani & $636(3.2)$ & $41(0.2)$ & $164(1.5)$ & $545(3.3)$ \\
\hline Bangladeshi & $297(1.5)$ & $14(0.1)$ & $147(1.3)$ & $130(0.8)$ \\
\hline Black Caribbean & $265(1.3)$ & $127(0.8)$ & $48(0.4)$ & $198(1.2)$ \\
\hline Black African & $670(3.4)$ & $112(0.7)$ & $94(0.8)$ & $520(3.1)$ \\
\hline Mixed & $328(1.7)$ & $280(1.7)$ & $124(1.1)$ & $293(1.8)$ \\
\hline Other & $938(4.8)$ & $241(1.4)$ & $284(2.5)$ & $993(6.0)$ \\
\hline Missing & 27 & 21 & 5 & 37 \\
\hline \multicolumn{5}{|l|}{ Understanding of English: } \\
\hline Fluent & $18044(92.3)$ & $16724(99.5)$ & $10927(97.1)$ & $15196(91.3)$ \\
\hline Some & $1130(5.8)$ & $75(0.4)$ & $273(2.4)$ & $1176(7.1)$ \\
\hline None & $380(1.9)$ & $15(0.1)$ & $55(0.5)$ & $274(1.6)$ \\
\hline Missing & 152 & 26 & 27 & 64 \\
\hline \multicolumn{5}{|l|}{ Marital or partner status: } \\
\hline Married or living with partner & $17097(88.2)$ & $16056(96.0)$ & $10444(93.6)$ & $15014(91.2)$ \\
\hline Single or unsupported by partner & $2289(11.8)$ & $673(4.0)$ & $718(6.4)$ & $1453(8.8)$ \\
\hline Missing & 320 & 111 & 120 & 243 \\
\hline \multicolumn{5}{|l|}{ Body mass index in pregnancy: } \\
\hline Mean (SD) & $24.4(4.0)$ & $24.0(3.7)$ & $24.1(3.7)$ & $24.0(3.8)$ \\
\hline Not recorded in maternity notes & $3566(18.1)$ & $3268(19.5)$ & $1861(16.5)$ & $2927(17.6)$ \\
\hline$<18.5$ & $570(2.9)$ & $321(1.9)$ & $234(2.1)$ & $438(2.6)$ \\
\hline $18.5-24.9$ & $8856(45.1)$ & $8155(48.7)$ & $5605(49.8)$ & $8218(49.4)$ \\
\hline $25.0-29.9$ & $4731(24.1)$ & $3776(22.5)$ & $2653(23.6)$ & $3789(22.8)$ \\
\hline $30.0-35.0$ & $1928(9.8)$ & $1226(7.3)$ & $912(8.1)$ & $1272(7.6)$ \\
\hline Missing & 55 & 94 & 17 & 66 \\
\hline \multicolumn{5}{|l|}{ Deprivation score (quintile) ${ }^{*}$ : } \\
\hline 1st (least deprived) & $3157(16.1)$ & $3688(22.1)$ & $2496(22.2)$ & $2535(15.2)$ \\
\hline 2nd & $3618(18.5)$ & $3483(20.8)$ & $2582(22.9)$ & $2648(15.9)$ \\
\hline $3 \mathrm{rd}$ & $3698(18.9)$ & $3650(21.8)$ & $2304(20.5)$ & 3245 (19.5) \\
\hline 4th & $4084(20.9)$ & $3336(19.9)$ & $2080(18.5)$ & $3852(23.1)$ \\
\hline 5th (most deprived) & $5023(25.7)$ & $2565(15.3)$ & $1789(15.9)$ & $4382(26.3)$ \\
\hline Missing & 126 & 118 & 31 & 48 \\
\hline
\end{tabular}


Table 1 (continued)

\begin{tabular}{|c|c|c|c|c|}
\hline & Obstetric unit ( $n=19706)$ & Home $(n=16840)$ & $\begin{array}{l}\text { Freestanding midwifery unit } \\
\qquad(\mathrm{n}=11 \text { 282) }\end{array}$ & $\begin{array}{l}\text { Alongside midwifery unit } \\
\qquad(n=16 \quad 710)\end{array}$ \\
\hline 0 & $10626(54.0)$ & $4568(27.2)$ & $5187(46.0)$ & $8350(50.1)$ \\
\hline 1 & $5757(29.3)$ & $6528(38.8)$ & $3913(34.7)$ & $5621(33.7)$ \\
\hline 2 & $2028(10.3)$ & $3663(21.8)$ & $1513(13.4)$ & $1933(11.6)$ \\
\hline$\geq 3$ & $1264(6.4)$ & 2065 (12.3) & $652(5.8)$ & 769 (4.6) \\
\hline Missing & 31 & 16 & 17 & 37 \\
\hline \multicolumn{5}{|l|}{ Gestation (completed weeks): } \\
\hline Mean (SD) & $39.8(1.1)$ & $39.8(1.0)$ & $39.8(1.0)$ & $39.7(1.0)$ \\
\hline 37 & 717 (3.6) & $378(2.3)$ & $315(2.8)$ & $474(2.8)$ \\
\hline 38 & $1969(10.0)$ & $1568(9.3)$ & $978(8.7)$ & $1565(9.4)$ \\
\hline 39 & 4557 (23.2) & 4089 (24.3) & $2669(23.7)$ & $4132(24.8)$ \\
\hline 40 & $6976(35.5)$ & $6596(39.3)$ & $4364(38.8)$ & $6492(39.0)$ \\
\hline 41 & $4908(25.0)$ & $3866(23.0)$ & $2821(25.1)$ & $3797(22.8)$ \\
\hline$\geq 42$ & $523(2.7)$ & $302(1.8)$ & $108(1.0)$ & $195(1.2)$ \\
\hline Missing† & 56 & 41 & 27 & 55 \\
\hline \multicolumn{5}{|l|}{$\begin{array}{l}\text { Complicating conditions identified at } \\
\text { start of care in labour: }\end{array}$} \\
\hline $\begin{array}{l}\text { Prolonged rupture of membranes } \\
(>18 \text { hours })\end{array}$ & $1462(7.4)$ & $395(2.4)$ & $231(2.1)$ & $383(2.3)$ \\
\hline Meconium stained liquor & $1254(6.4)$ & $242(1.5)$ & $140(1.2)$ & $233(1.4)$ \\
\hline Proteinuria $(\geq 1+)$ & $347(1.8)$ & $80(0.5)$ & $110(1.0)$ & $370(2.2)$ \\
\hline Hypertension & $502(2.6)$ & $92(0.6)$ & $78(0.7)$ & $113(0.7)$ \\
\hline Abnormal vaginal bleeding & $274(1.4)$ & $41(0.2)$ & $22(0.2)$ & $37(0.2)$ \\
\hline Non-cephalic presentation & $108(0.6)$ & $37(0.2)$ & $25(0.2)$ & $29(0.2)$ \\
\hline Abnormal fetal heart rate & $393(2.0)$ & $68(0.4)$ & $52(0.5)$ & $65(0.4)$ \\
\hline Other complications & $54(0.3)$ & $14(0.1)$ & $17(0.2)$ & $17(0.1)$ \\
\hline \multicolumn{5}{|l|}{ Complications per woman: } \\
\hline 0 & $15794(80.5)$ & $15757(94.6)$ & $10643(94.5)$ & $15512(93.1)$ \\
\hline 1 & $3345(17.0)$ & $847(5.1)$ & $572(5.1)$ & $1078(6.5)$ \\
\hline$\geq 2$ & $490(2.5)$ & $51(0.3)$ & $50(0.4)$ & $78(0.5)$ \\
\hline Missing & 77 & 185 & 17 & 42 \\
\hline
\end{tabular}

*Measured with index of multiple deprivation.

†lf the recorded "estimated date of delivery" gave a gestational age of $\leq 31^{+6}$ weeks, the birth weight was compared with growth reference centiles, ${ }^{17}$ and if the birth weight was $>95$ th centile for the recorded gestational age and $>5$ th centile for a gestation of $37^{+0}$ weeks, the birth was assumed to be term but the gestation was recoded as missing. A gestation of $>44^{+0}$ weeks was considered implausible and also recorded as missing. 
Table 2| Transfers during labour or immediately after birth among healthy women with low risk pregnancies by their planned place of birth at start of care in labour. Values are numbers (percentages) of women

Home ( $n=16$ 840) Freestanding midwifery unit $(n=11282)$ Alongside midwifery unit $(n=16710)$

All women

\begin{tabular}{|c|c|c|c|}
\hline Transferred before delivery & $2387(14.2)$ & $1863(16.5)$ & $3539(21.2)$ \\
\hline Transferred after delivery & $1046(6.2)$ & $545(4.8)$ & $719(4.3)$ \\
\hline Timing of transfer missing & $97(0.6)$ & $60(0.5)$ & $152(0.9)$ \\
\hline All transferred & $3530(21.0)$ & $2468(21.9)$ & $4410(26.4)$ \\
\hline Nulliparous women & $(n=4568)$ & $(n=5187)$ & $(n=8350)$ \\
\hline Transferred before delivery & $1605(35.1)$ & $1535(29.6)$ & $2825(33.8)$ \\
\hline Transferred after delivery & $407(8.9)$ & $306(5.9)$ & $427(5.1)$ \\
\hline Timing of transfer missing & $45(1.0)$ & $43(0.8)$ & $108(1.3)$ \\
\hline All transferred & $2057(45.0)$ & $1884(36.3)$ & $3360(40.2)$ \\
\hline Multiparous women & $(n=12256)$ & $(n=6078)$ & $(n=8323)$ \\
\hline Transferred before delivery & $782(6.4)$ & $321(5.3)$ & $707(8.5)$ \\
\hline Transferred after delivery & $639(5.2)$ & $238(3.9)$ & $291(3.5)$ \\
\hline Timing of transfer missing & $51(0.4)$ & $14(0.2)$ & $43(0.5)$ \\
\hline All transferred & $1472(12.0)$ & $573(9.4)$ & $1041(12.5)$ \\
\hline
\end{tabular}

A small proportion of births planned in an obstetric unit also involved a transfer $(n=135(0.7 \%))$. 
Table 3| Primary outcome* for babies of heathy women with low risk pregnancies by their planned place of birth at start of care in labour. Categorised by parity for all women and restricted to those without complicating conditions at start of care in labour

\begin{tabular}{|c|c|c|c|c|}
\hline \multirow[b]{2}{*}{ Planned place of birth } & \multirow[b]{2}{*}{ No of events/births } & \multirow{2}{*}{$\begin{array}{c}\text { Incidence of events/1000 } \\
(95 \% \mathrm{Cl}) \dagger\end{array}$} & \multicolumn{2}{|c|}{ Odds ratio $(95 \% \mathrm{Cl}) \dagger$} \\
\hline & & & Unadjusted & Adjusted $\ddagger$ \\
\hline \multicolumn{5}{|l|}{ All women } \\
\hline Total: & $250 / 63827$ & 4.3 (3.3 to 5.5$)$ & \multicolumn{2}{|c|}{$(\mathrm{n}=62$ 036)§ } \\
\hline Obstetric unit & $81 / 19551$ & 4.4 (3.2 to 5.9$)$ & 1.00 & 1.00 \\
\hline Home & 70/16 553 & $4.2(3.2$ to 5.4$)$ & 0.96 (0.65 to 1.42$)$ & $1.16(0.76$ to 1.77$)$ \\
\hline Freestanding midwifery unit & $41 / 11199$ & $3.5(2.5$ to 4.9$)$ & $0.82(0.52$ to 1.28$)$ & $0.92(0.58$ to 1.46$)$ \\
\hline Alongside midwifery unit & $58 / 16524$ & 3.6 (2.6 to 4.9$)$ & $0.84(0.54$ to 1.30$)$ & $0.92(0.60$ to 1.39$)$ \\
\hline Nulliparous womenף: & $153 / 28443$ & $5.3(4.0$ to 7.0$)$ & \multicolumn{2}{|c|}{$(n=27669) \S$} \\
\hline Obstetric unit & $52 / 10541$ & 5.3 (3.9 to 7.3 ) & 1.00 & 1.00 \\
\hline Home & $39 / 4488$ & $9.3(6.5$ to 13.1$)$ & 1.76 (1.10 to 2.82$)$ & 1.75 (1.07 to 2.86$)$ \\
\hline Freestanding midwifery unit & $24 / 5158$ & $4.5(2.8$ to 7.1$)$ & 0.85 (0.49 to 1.48$)$ & $0.91(0.52$ to 1.60$)$ \\
\hline Alongside midwifery unit & $38 / 8256$ & 4.7 (3.1 to 7.2 ) & 0.90 (0.53 to 1.54$)$ & $0.96(0.58$ to 1.61$)$ \\
\hline Multiparous womenף: & $97 / 35289$ & 3.1 (2.2 to 4.5$)$ & \multicolumn{2}{|c|}{$(\mathrm{n}=34367) \S$} \\
\hline Obstetric unit & $29 / 8980$ & $3.3(2.2$ to 5.0$)$ & 1.00 & 1.00 \\
\hline Home & $31 / 12050$ & 2.3 (1.6 to 3.2$)$ & $0.70(0.40$ to 1.21$)$ & $0.72(0.41$ to 1.27$)$ \\
\hline Freestanding midwifery unit & $17 / 6025$ & 2.7 (1.6 to 4.6$)$ & $0.86(0.44$ to 1.69$)$ & $0.91(0.46$ to 1.80$)$ \\
\hline Alongside midwifery unit & $20 / 8234$ & $2.4(1.4$ to 4.3$)$ & 0.77 (0.38 to 1.57$)$ & $0.81(0.40$ to 1.62$)$ \\
\hline \multicolumn{5}{|c|}{ Women without complicating conditions at start of care in labour } \\
\hline Total: & $199 / 57127$ & $3.1(2.4$ to 4.0$)$ & \multicolumn{2}{|c|}{$(n=55572) \S$} \\
\hline Obstetric unit & $48 / 15676$ & 3.1 (2.2 to 4.2$)$ & 1.00 & 1.00 \\
\hline Home & $62 / 15538$ & $4.0(3.0$ to 5.3$)$ & $1.34(0.88$ to 2.05$)$ & 1.59 (1.01 to 2.52$)$ \\
\hline Freestanding midwifery unit & $35 / 10571$ & $3.2(2.3$ to 4.6$)$ & $1.11(0.69$ to 1.77$)$ & $1.22(0.76$ to 1.96$)$ \\
\hline Alongside midwifery unit & $54 / 15342$ & $3.4(2.4$ to 4.9$)$ & $1.19(0.74$ to 1.91$)$ & $1.26(0.80$ to 1.99$)$ \\
\hline Nulliparous women**: & $121 / 24384$ & 3.8 (2.8 to 5.1$)$ & \multicolumn{2}{|c|}{$(n=23742) \S$} \\
\hline Obstetric unit & $28 / 8018$ & 3.5 (2.4 to 5.1$)$ & 1.00 & 1.00 \\
\hline Home & $36 / 4063$ & 9.5 (6.6 to 13.7$)$ & 2.81 (1.66 to 4.76$)$ & 2.80 (1.59 to 4.92$)$ \\
\hline Freestanding midwifery unit & $22 / 4785$ & $4.5(2.8$ to 7.4$)$ & $1.33(0.72$ to 2.46$)$ & $1.40(0.74$ to 2.65$)$ \\
\hline Alongside midwifery unit & $35 / 7518$ & $4.4(2.7$ to 7.0$)$ & 1.31 (0.71 to 2.39$)$ & $1.38(0.75$ to 2.52$)$ \\
\hline Multiparous women**: & 78/32 662 & 2.5 (1.6 to 3.9$)$ & \multicolumn{2}{|c|}{$(\mathrm{n}=31830) \S$} \\
\hline Obstetric unit & $20 / 7637$ & 2.6 (1.5 to 4.4$)$ & 1.00 & 1.00 \\
\hline Home & $26 / 11461$ & $2.0(1.4$ to 2.9$)$ & $0.80(0.41$ to 1.54$)$ & $0.83(0.44$ to 1.58$)$ \\
\hline Freestanding midwifery unit & $13 / 5772$ & $2.2(1.3$ to 3.8$)$ & $0.90(0.42$ to 1.94$)$ & $0.97(0.46$ to 2.04$)$ \\
\hline Alongside midwifery unit & 19/7792 & 2.5 (1.4 to 4.5$)$ & $1.04(0.47$ to 2.30$)$ & 1.09 (0.50 to 2.39$)$ \\
\hline
\end{tabular}

*Primary outcome was perinatal mortality and intrapartum related neonatal morbidities (stillbirth after start of care in labour, early neonatal death, neonatal encephalopathy, meconium aspiration syndrome, brachial plexus injury, fractured humerus or clavicle).

†Weighted to reflect each unit's duration of participation and probability of being sampled; confidence intervals take account of the clustered nature of the data. $\ddagger$ Adjusted for maternal age, ethnic group, understanding of English, marital or partner status, body mass index, deprivation score quintile, previous pregnancies, and weeks of gestation.

§Restricted to women who were not missing any potential confounder data.

ITest for statistical interaction between planned place of birth and parity. $\mathrm{P}$ values for parity adjusted regression tests of heterogeneity: overall 0.06 ; pairwise $(v$ obstetric unit) for home 0.01 , freestanding midwifery unit 0.99 , and alongside midwifery unit 0.69 .

${ }^{* *}$ Test for statistical interaction between planned place of birth and parity. $\mathrm{P}$ values for parity adjusted regression tests of heterogeneity: overall 0.03 ; pairwise $(v$ obstetric unit) for home 0.006 , freestanding midwifery unit 0.47 , and alongside midwifery unit 0.66 . 


\begin{tabular}{|c|c|c|c|c|}
\hline \multirow{2}{*}{$\begin{array}{l}\text { Intervention and planned place of } \\
\text { birth }\end{array}$} & \multirow[b]{2}{*}{ No of events/births } & \multirow{2}{*}{$\begin{array}{l}\text { Incidence of events/100 (99\% } \\
\text { Cl) })^{\star}\end{array}$} & \multicolumn{2}{|c|}{ Odds ratio $(99 \% \mathrm{Cl})^{*}$} \\
\hline & & & Unadjusted & Adjusted $†$ \\
\hline Spontaneous vertex birth: & 54 798/64 483 & 76.4 (73.8 to 78.7$)$ & \multicolumn{2}{|c|}{$(\mathrm{n}=62592) \ddagger$} \\
\hline Obstetric unit & $14645 / 19688$ & 73.8 (71.1 to 76.4 ) & 1.00 & 1.00 \\
\hline Home & $15590 / 16825$ & 92.8 (91.7 to 93.7$)$ & 4.49 (3.67 to 5.49$)$ & 3.61 (2.97 to 4.38$)$ \\
\hline Freestanding midwifery unit & $10150 / 11280$ & 90.7 (89.1 to 92.0$)$ & 3.45 (2.76 to 4.31$)$ & 3.38 (2.70 to 4.25$)$ \\
\hline Alongside midwifery unit & $14413 / 16690$ & 85.9 (83.7 to 87.9$)$ & $2.16(1.74$ to 2.70$)$ & 2.22 (1.76 to 2.81$)$ \\
\hline Vaginal breech birth: & $171 / 64483$ & $0.2(0.2$ to 0.3$)$ & \multicolumn{2}{|c|}{$(\mathrm{n}=62592) \ddagger$} \\
\hline Obstetric unit & $43 / 19688$ & $0.2(0.1$ to 0.3$)$ & 1.00 & 1.00 \\
\hline Home & $63 / 16825$ & $0.4(0.3$ to 0.5$)$ & $1.83(0.97$ to 3.45$)$ & 2.13 (1.15 to 3.96$)$ \\
\hline Freestanding midwifery unit & $39 / 11280$ & $0.4(0.2$ to 0.6$)$ & 1.79 (0.86 to 3.72$)$ & 2.00 (1.00 to 3.99$)$ \\
\hline Alongside midwifery unit & $26 / 16690$ & $0.2(0.1$ to 0.3$)$ & 0.94 (0.43 to 2.07$)$ & 0.94 (0.44 to 2.04$)$ \\
\hline Ventouse delivery: & $2953 / 64483$ & 7.3 (5.9 to 9.0$)$ & \multicolumn{2}{|c|}{$(n=62592) \ddagger$} \\
\hline Obstetric unit & $1535 / 19688$ & 8.1 (6.4 to 10.1$)$ & 1.00 & 1.00 \\
\hline Home & $342 / 16825$ & 2.0 (1.6 to 2.5$)$ & 0.24 (0.17 to 0.33$)$ & 0.29 (0.21 to 0.40$)$ \\
\hline Freestanding midwifery unit & $321 / 11280$ & 2.7 (2.0 to 3.5 ) & 0.31 (0.21 to 0.46$)$ & 0.32 (0.22 to 0.47$)$ \\
\hline Alongside midwifery unit & $755 / 16690$ & $4.8(3.6$ to 6.2$)$ & 0.57 (0.39 to 0.83$)$ & 0.56 (0.39 to 0.82 ) \\
\hline Forceps delivery: & $2813 / 64483$ & $6.2(5.1$ to 7.6$)$ & \multicolumn{2}{|c|}{$(\mathrm{n}=62$ 592)‡ } \\
\hline Obstetric unit & $1307 / 19688$ & $6.8(5.4$ to 8.4$)$ & 1.00 & 1.00 \\
\hline Home & $372 / 16825$ & $2.1(1.8$ to 2.5$)$ & $0.30(0.22$ to 0.40$)$ & $0.43(0.32$ to 0.57$)$ \\
\hline Freestanding midwifery unit & $365 / 11280$ & $2.9(2.3$ to 3.7$)$ & 0.41 (0.29 to 0.58$)$ & 0.45 (0.32 to 0.63 ) \\
\hline Alongside midwifery unit & $769 / 16690$ & 4.7 (3.5 to 6.4$)$ & 0.68 (0.45 to 1.01$)$ & 0.70 (0.46 to 1.05$)$ \\
\hline Intrapartum caesarean section: & $3748 / 64483$ & 9.9 (8.4 to 11.5$)$ & \multicolumn{2}{|c|}{$(\mathrm{n}=62$ 592)‡ } \\
\hline Obstetric unit & $2158 / 19688$ & 11.1 (9.5 to 13.0$)$ & 1.00 & 1.00 \\
\hline Home & $458 / 16825$ & $2.8(2.3$ to 3.4$)$ & $0.23(0.17$ to 0.30$)$ & 0.31 (0.23 to 0.41$)$ \\
\hline Freestanding midwifery unit & $405 / 11280$ & 3.5 (2.8 to 4.2$)$ & $0.28(0.21$ to 0.37$)$ & 0.32 (0.24 to 0.42$)$ \\
\hline Alongside midwifery unit & $727 / 16690$ & 4.4 (3.5 to 5.5$)$ & 0.37 (0.28 to 0.49$)$ & 0.39 (0.29 to 0.53$)$ \\
\hline $\begin{array}{l}\text { Third or fourth degree perineal } \\
\text { trauma: }\end{array}$ & $1737 / 64354$ & $3.1(2.7$ to 3.6$)$ & \multicolumn{2}{|c|}{$(\mathrm{n}=62$ 482) } \\
\hline Obstetric unit & $625 / 19638$ & $3.2(2.7$ to 3.7$)$ & 1.00 & 1.00 \\
\hline Home & $318 / 16800$ & 1.9 (1.6 to 2.3$)$ & 0.58 (0.45 to 0.76$)$ & 0.77 (0.57 to 1.05$)$ \\
\hline Freestanding midwifery unit & $259 / 11262$ & 2.3 (1.9 to 2.9$)$ & $0.72(0.56$ to 0.94$)$ & 0.78 (0.58 to 1.05$)$ \\
\hline Alongside midwifery unit & $535 / 16654$ & $3.2(2.6$ to 4.0$)$ & $1.02(0.77$ to 1.34$)$ & 1.04 (0.79 to 1.38$)$ \\
\hline Blood transfusion: & $545 / 64044$ & $1.2(0.9$ to 1.4$)$ & \multicolumn{2}{|c|}{$(n=62219) \ddagger$} \\
\hline Obstetric unit & $241 / 19579$ & $1.2(1.0$ to 1.6$)$ & 1.00 & 1.00 \\
\hline Home & $101 / 16687$ & $0.6(0.5$ to 0.9$)$ & $0.54(0.36$ to 0.80$)$ & 0.72 (0.47 to 1.12$)$ \\
\hline Freestanding midwifery unit & $67 / 11230$ & $0.5(0.4$ to 0.7$)$ & $0.42(0.28$ to 0.64$)$ & $0.48(0.32$ to 0.73$)$ \\
\hline Alongside midwifery unit & $136 / 16548$ & $0.9(0.7$ to 1.2$)$ & $0.72(0.52$ to 1.00$)$ & 0.75 (0.55 to 1.02$)$ \\
\hline Admission to a higher level of care: & $281 / 64538$ & $0.6(0.4$ to 1.0$)$ & \multicolumn{2}{|c|}{$(\mathrm{n}=62635) \ddagger$} \\
\hline Obstetric unit & $117 / 19706$ & $0.6(0.3$ to 1.1$)$ & 1.00 & 1.00 \\
\hline Home & $58 / 16840$ & $0.4(0.2$ to 0.6$)$ & 0.61 (0.29 to 1.27$)$ & 0.77 (0.36 to 1.65$)$ \\
\hline Freestanding midwifery unit & $24 / 11282$ & $0.2(0.1$ to 0.3$)$ & 0.27 (0.11 to 0.69$)$ & $0.32(0.13$ to 0.84$)$ \\
\hline Alongside midwifery unit & $82 / 16710$ & 0.7 (0.3 to 1.5$)$ & 1.14 (0.43 to 3.03$)$ & 1.17 (0.46 to 2.99$)$ \\
\hline Syntocinon augmentation: & $8078 / 64174$ & 20.9 (18.7 to 23.3$)$ & \multicolumn{2}{|c|}{$(n=62314) \ddagger$} \\
\hline Obstetric unit & $4549 / 19483$ & 23.5 (21.1 to 26.2$)$ & 1.00 & 1.00 \\
\hline Home & $943 / 16794$ & $5.4(4.8$ to 6.1$)$ & $0.19(0.15$ to 0.23$)$ & 0.25 (0.21 to 0.31$)$ \\
\hline Freestanding midwifery unit & $878 / 11238$ & $7.1(6.0$ to 8.5$)$ & 0.25 (0.19 to 0.32$)$ & 0.26 (0.20 to 0.33$)$ \\
\hline Alongside midwifery unit & $1708 / 16659$ & 10.3 (8.9 to 11.8$)$ & $0.38(0.30$ to 0.46$)$ & 0.37 (0.30 to 0.46$)$ \\
\hline Immersion in water for pain relief: & $17674 / 64086$ & $13.4(10.5$ to 16.9$)$ & \multicolumn{2}{|c|}{$(\mathrm{n}=62214) \ddagger$} \\
\hline Obstetric unit & $1836 / 19680$ & 9.1 (6.4 to 12.6$)$ & 1.00 & 1.00 \\
\hline
\end{tabular}


Table 4 (continued)

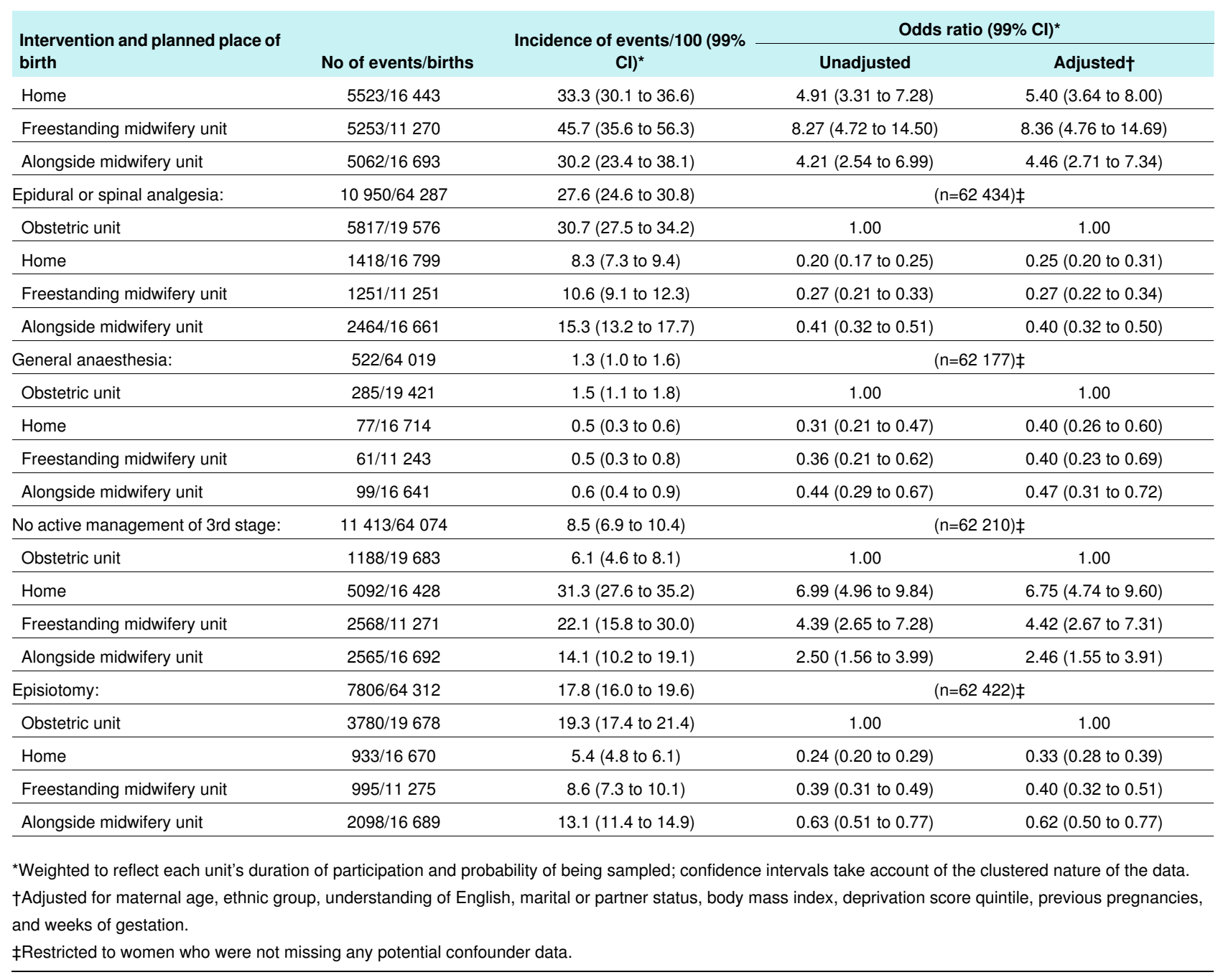


Table 5| "Normal births"* for healthy women with low risk pregnancies by their planned place of birth at start of care in labour. Results for all women and restricted to those without complicating conditions at start of care in labour

\begin{tabular}{|c|c|c|c|c|}
\hline \multirow[b]{2}{*}{ Planned place of birth } & \multirow[b]{2}{*}{ No of events/births } & \multirow{2}{*}{$\begin{array}{c}\text { Incidence of events/100 (99\% } \\
\mathrm{Cl}) \dagger\end{array}$} & \multicolumn{2}{|c|}{ Odds ratio $(99 \% \mathrm{Cl}) \dagger$} \\
\hline & & & Unadjusted & Adjusted‡ \\
\hline \multicolumn{5}{|l|}{ All women } \\
\hline Total: & $48080 / 64105$ & $61 \cdot 5(58 \cdot 2$ to $64 \cdot 7)$ & \multicolumn{2}{|c|}{$(n=62253) \S$} \\
\hline Obstetric unit & $11392 / 19570$ & $57 \cdot 6(54 \cdot 1$ to $60 \cdot 9)$ & 1.00 & 1.00 \\
\hline Home & $14566 / 16619$ & $87 \cdot 9(86 \cdot 6$ to $89 \cdot 1)$ & $5 \cdot 30(4 \cdot 41$ to $6 \cdot 36)$ & $4.47(3.74$ to 5.36$)$ \\
\hline Freestanding midwifery unit & $9335 / 11258$ & $83 \cdot 3(81 \cdot 3$ to $85 \cdot 1)$ & $3.68(3.03$ to 4.46$)$ & $3.86(3.16$ to 4.72$)$ \\
\hline Alongside midwifery unit & $12787 / 16658$ & $76.0(73.3$ to $78 \cdot 6)$ & $2.33(1.91$ to 2.84$)$ & $2.50(2.02$ to 3.08$)$ \\
\hline \multicolumn{5}{|c|}{ Women without complicating conditions at start of care in labour } \\
\hline Total: & $44658 / 57452$ & $65 \cdot 9(62 \cdot 6$ to $69 \cdot 1)$ & \multicolumn{2}{|c|}{$(\mathrm{n}=55$ 849)§ } \\
\hline Obstetric unit & $9840 / 15689$ & $62 \cdot 2(58 \cdot 6$ to $65 \cdot 6)$ & 1.00 & 1.00 \\
\hline Home & $13902 / 15675$ & $89 \cdot 0(87 \cdot 7$ to $90 \cdot 1)$ & $4 \cdot 85(4 \cdot 00$ to $5 \cdot 90)$ & $4.12(3.37$ to 5.04$)$ \\
\hline Freestanding midwifery unit & $8892 / 10620$ & $84 \cdot 1(82 \cdot 0$ to $86 \cdot 0)$ & 3.22 (2.61 to 3.96$)$ & $3.42(2.74$ to 4.27$)$ \\
\hline Alongside midwifery unit & $12024 / 15468$ & $77 \cdot 1(74 \cdot 5$ to $79 \cdot 6)$ & $2 \cdot 04(1.66$ to $2 \cdot 51)$ & $2 \cdot 21(1.77$ to $2 \cdot 75)$ \\
\hline
\end{tabular}

*Defined as a birth without induction of labour, epidural or spinal analgesia, general anaesthesia, forceps or ventouse delivery, caesarean section, or episiotomy. ${ }^{9}$

${ }^{10}$ Because normal birth is common, the odds ratios exaggerate the size of the association between planned place of birth and normal birth and do not reflect the ratio of the incidence of the outcome.

tWeighted to reflect each unit's duration of participation and probability of being sampled; confidence intervals take account of the clustered nature of the data. $\ddagger$ Adjusted for maternal age, ethnic group, understanding of English, marital or partner status, body mass index, deprivation score quintile, previous pregnancies, and weeks of gestation.

$\S$ Restricted to women who were not missing any potential confounder data. 


\section{Figure}

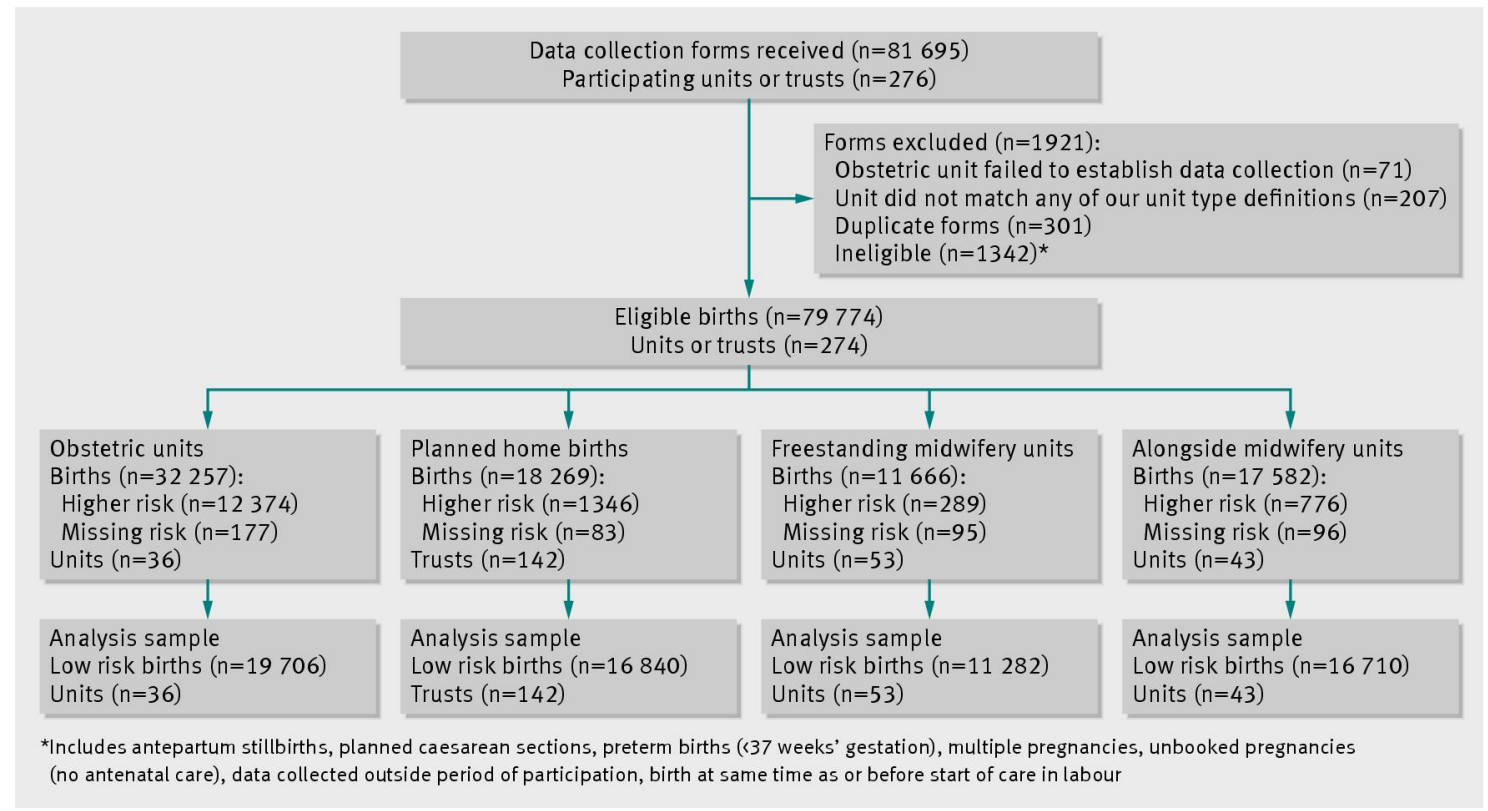

Flow of participants through study 